\title{
A Literature Review of Understanding and Supporting Students with Attention Deficit Hyperactivity Disorder in the Classroom
}

Kerilyn Creelman

University of Alberta, kerilyn@ualberta.ca

Follow this and additional works at: https://pdxscholar.library.pdx.edu/nwjte

Part of the Disability and Equity in Education Commons, Educational Psychology Commons, Elementary Education Commons, Secondary Education Commons, and the Special Education and Teaching Commons

Let us know how access to this document benefits you.

\section{Recommended Citation}

Creelman, Kerilyn (2021) "A Literature Review of Understanding and Supporting Students with Attention Deficit Hyperactivity Disorder in the Classroom," Northwest Journal of Teacher Education: Vol. 16 : Iss. 1 , Article 3.

DOI: https://doi.org/10.15760/nwjte.2021.16.1.3

This open access Article is distributed under the terms of the Creative Commons Attribution-NonCommercialShareAlike 4.0 International License (CC BY-NC-SA 4.0). All documents in PDXScholar should meet accessibility standards. If we can make this document more accessible to you, contact our team. 


\title{
A Literature Review of Understanding and Supporting Students with Attention Deficit Hyperactivity Disorder in the Classroom
}

\begin{abstract}
The effects of Attention Deficit Hyperactivity Disorder (ADHD) has on academic performance are evident. This mini-literature review aims to gain insight into which parts of ADHD affects a student's academic achievement and to provide suggestions to use to assist closing the academic gap between students with ADHD and neurotypical students. ADHD is a neurodevelopmental disorder that is increasing in diagnosis within children. ADHD affects a child's academic performance, creating a deficit measured in years, and grows as children continue into their high school careers. ADHD-Inattentive affects academic performance the most out of the three subtypes of ADHD. Medication has shown to have positive impacts on academic performance by increasing a student's ability to focus and notice details within their schoolwork. Deficits in executive functioning skills, which students with ADHD often portray, contributes to poor academic performance. Areas of executive functioning that affect school accomplishment include working memory, organization and planning, goal setting, and persistence. The paper concludes that supports in these executive functioning deficit areas, implemented at the school level, can improve a student's schooling success.
\end{abstract}

\section{Keywords}

disability, equity, educational psychology, ADHD, supports

\section{Creative Commons License}

cc) (i) (2)

This work is licensed under a Creative Commons Attribution-NonCommercial-Share Alike 4.0 International License. 


\section{Introduction}

Attention Deficit Hyperactivity Disorder (ADHD) is currently one of the most commonly diagnosed childhood disorders. It can involve up to $8 \%$ of the population. (American Psychiatric Association, 2017). The American Psychiatric Association (2017) lists three types of ADHD: ADHD-Inattentive, ADHDHyperactivity/Impulsivity, and ADHD-Combined. ADHD is considered a neurodevelopmental disorder as it is predominantly a consequence of a delay in specific mental abilities (Barkley, 2016). There are parts of the brain that are delayed or dysfunctional in maturation (Barkley, 2016; Keilow, Holm, \& Fallsesen, 2018). Grossberg (2015) points out that the "brain's prefrontal cortex may develop more slowly in people with ADHD" (loc. 284). She continues to discuss how researchers have indicated that people with ADHD may have "irregularities in the way certain [neuro]transmitters [in the brain] function" (loc. 284).

An area that students with ADHD seem to struggle is academic performance (Bussing et al., 2012; Costa et al., 2014; Daley \& Birchwood, 2009; Keilow, Holm, \& Fallsesen, 2018, Lundervold, Meza, Hysing, \& Hinshaw, 2017; Perrin, Heller, \& Loe, 2019; Santosh \& Rachana, 2019; Schmiedeler \& Schneider, 2013; Takri \& Jaiswal, 2019). As early as preschool, students with ADHD are showing delays in academics (Perrin, Heller, \& Loe, 2019; Schmiedeler \& Schneider, 2014). Keilow, Holm, \& Fallsesen (2018) mentions that "previous studies have found that children diagnosed with ADHD on average attain 2.2 to 2.5 years less schooling than non-ADHD peers" (p. 2). The children's lack of attention, inability to focus, and difficulty completing schoolwork contribute to the achievement gap between students with ADHD and their peers. The Center for Disease Control and Prevention (CDC) (2019) states that $62 \%$ of children who have ADHD take medication to help them function in their everyday lives. Keilow, Holm \& Fallsesen (2018), McCormick (2003), and Prasad et al. (2012) give us insight on how medication affects students' behavior and allows them to approach academics in a different light. Colomer, Bergenguer, Rosello, Baixauli, and Miranda (2017), Johnson and Reid (2011), van der Donk, Hiemstra-Beernink, Tjeenk-Kalff, van der Leij, and Lindauer (2013), as well as Barkley $(2013,2016)$ and Guare, Dawson, and Guare (2013) discuss how ADHD affects a child's executive functioning skills (EF). Students struggle with life's daily tasks and keeping up with the expectations that the world has placed on them. For example, students with EF deficits tend to be more disorganized with their schoolwork or continuously lose their keys. Deficits in EF skills considerably affect their academic performance, often under adverse circumstances. 


\section{ADHD and Academic Performance}

Fergusson (1997) suggests a connection between ADHD and poor academic accomplishment (p. 203). In support, Costa et al. (2014) claims that "poor academic performance is a usual feature of children with ADHD" (p. 313). Students with ADHD tend to have a lower grade point average (GPA) (Keilow, Holm, \& Fallesen, 2018) and perform lower in reading, writing, and math than do their neurotypical peers (Bussing et al., 2012; Costa et al., 2014). Through longitudinal data, Bussing et al. (2012) found that students with ADHD received more special education services than did other students. They learned that scores from students with ADHD were equivalent to typical students on third-grade standardized assessments, but the achievement gap grew more significant as the students progressed through the grades (Bussing et al., 2012). Although students with ADHD showed growth over their schooling, "statistical significance testing confirmed that students with ADHD plus special education [assignation] performed worse" (Bussing et al., 2012, p. 138) in achievement trajectories. Santosh and Rachana (2019), Schmiedeler and Scheider (2014) and Bussing and colleague's (2012) argue that the inattentive part of ADHD has the most significant effect on academic performance. The inattentive side of ADHD accounts for failing to finish work, failing to show close attention to details, daydreaming, or not being organized (Barkley, 2016, American Psychiatric Association, 2017). Lundervold, Meza, Hysing, \& Hinshaw's (2017) longitudinal survey examined how inattention in childhood may predict future high school academic achievement. They continue to correlate inattention in a child's early years with negative consequences in the future (Lundervold, Meza, Hysing, \& Hinshaw, 2017). In their research on executive function skills, Klenberg, Hokkanen, Lahti-Nuuttila, and Närhi (2016) maintain that students with ADHDInattentive had difficulty with skills that would assist academic performance, such as sustained attention.

\section{ADHD Medications and its Impact on Academic Performance}

Many children diagnosed with ADHD are prescribed medication to help them with their inattentiveness and/or hyperactivity/impulsivity. Popular medications that are prescribed are stimulants, including methylphenidate and amphetamine (American Psychiatric Association, 2017). Other children may take non-stimulant medications. The medications help to balance the chemicals used by neurotransmitters (Barkley, 2013). Children may experience calmness, ability to focus, and may begin to notice details they had not noticed before. Dodson (2019) claims that the right stimulant given at the optimal dose can have an effect size of 2.1. Effect size is the statistical concept that measures the strength of the 
relationship between two variables (Fan, 2001). According to Dodson (2019), most medications will fall between 0.4 (barely detectable changes) and a 1.0 (a strong therapeutic response). Therefore, an effect size of 2.1 can be life-changing. In their review and meta-analysis, Prasad et al. (2012) found that, in terms of ontask behavior within the class, there was "support [for] the beneficial effects of treatment with methylphenidate, mixed amphetamine formulations and dexamfetamine [stimulant medications]" (p. 212). They also concluded that medication treatment aided the amount of seatwork the students diagnosed with ADHD were able to complete (Prasad et al., 2012). However, improvements in the accuracy of course work were not consistent - showing improvements in mathematics, but not in reading and spelling (Prasad et al., 2012). McCormick's (2003) case study showed similar conclusions - stimulant medications "did not significantly improve the outcome measures (GPAs)" (p. 623). Prasad et al. (2012) note that further studies using non-stimulant medications should be considered.

Keilow, Holm \& Fallsesen (2018) compared the effects of three types of medical treatment patterns: Discontinued Pharmacological Treatment (DPT) (control group), Ambiguous Pharmacological Treatment (APT) (partial compliance group), and Continuous Pharmacological Treatment (CPT) (treatment group). All three groups were given stimulant medications. Upon completing a regression analysis of their collected data, Keilow, Holm \& Fallsesen (2018) reported that "children who follow continuous treatment (CPT) have significantly higher exam GPAs compared to those who discontinue treatment partly (APT)" (p. 10). Their conclusions support the overall positive effect of medical action on long-term academic performance. However, Keilow, Holm \& Fallsesen (2018) acknowledge that GPAs probably reflect both academic performance and student behavior, whereas Prasad et al.'s (2012) and McCormick's (2003) studies separated the two. In a mixed-methods study, Miklos, Futo, Komaromy, and Balazs (2019) discovered that children who were unmedicated performed significantly worse in executive functioning activities than their typical nonADHD peers. Miklos, Futo, Komaromy, and Balazs' (2019) research continues to support the use of medication to assist students in combatting executive functioning deficits.

\section{ADHD and Executive Functioning Skills}

Deficits in EF skills could play a part in the underachievement in academic performance of students with ADHD. EFs are "cognitive processes necessary for complex goal-directed behavior" (Johnson \& Reid, 2011, p. 62). Deficits in EF skills should be a concern because these skills are necessary to succeed in school. Daley and Birchwood (2009) found that, "EFs were shown to mediate the 
relationship between inattention and early academic skills" (p. 459). They continue to suggest that in order to improve academic performance, interventions should focus on EF shortcomings (Daley \& Birchwood, 2009). Klenberg, Hokkanen, Lahti-Nuuttila, and Närhi's (2016) survey of EF skills with teacher rating scales showed that both ADHD-Inattentive and ADHD-Combined displayed significantly worse scores than those of their non-ADHD peers. These results coincide with Barkley's (2013) "view of ADHD as a disorder of executive functioning and the self-regulation it provides" (p. 26), which thus affects academic achievement.

\section{ADHD Affects EF Skills in School}

Colomer, Bergenguer, Rosello, Baixauli, and Miranda's (2017) findings revealed, "significant moderate to large correlations between most of the learning behaviors and both EF and ADHD symptoms" (p. 7). Identifying how learning behaviors can affect academic performance, and targeting changes in EFs and learning behaviors could improve academic performance (Colomer, Bergenguer, Rosello, Baixauli, \& Miranda, 2017; Daley \& Birchwood, 2009; Johnson \& Reid, 2011). Students need to be made aware of the EFs that are necessary for appropriate classroom behavior, so that they can gain more awareness of their own learning behavior (van der Donk, Hiemstra-Beernink, Tjeenk-Kalff, van der Leij, \& Lindauer, 2013). Within the school environment, the executive functioning skills affected include, but are not limited to the following: working memory, organization, and planning, goal setting, and persistence.

\section{Working Memory}

Working memory problems and ADHD both contribute to the lower academic performance seen by students with ADHD (van der Donk, Hiemstra-Beernink, Tjeenk-Kalff, van der Leij, \& Lindauer, 2013). Working memory involves two separate skills: a) being able to store information in mind all the while carrying out complicated activities; and b) drawing on past experience/learning and using it to the present situation or for future events (Guare, Dawson, \& Guare, 2013). Students without ADHD can easily store large or several pieces of information in their memory. For students with ADHD, working memory is delayed or impaired, and storing information in their working memory can become challenging. One way to assist students with ADHD is to "externalize" that information (Barkley, 2016, loc. 399). Externalizing information is often seen through the development of lists, use of planners, schedule completion, and the displaying of rules. By relieving the capacity for working memory to store the given information, ADHD students can then focus on other learning behaviors related to academic 
performance. Another way to ease the strain of holding large amounts of information in working memory is to provide single-step directions, and having the student paraphrase instructions back to the teacher (Guare, Dawson, \& Guare, 2013).

\section{Organization and Planning}

Organization and planning play significant roles in a student's academic career. Students with ADHD often take the time to make a rough plan for their activities (Johnson \& Reid, 2011). However, possibly due to impulsivity, they will not reflect on which behaviors are essential to complete a particular activity. Therefore, students with ADHD will follow their impulse when embarking on a particular activity. Even when students are encouraged and guided to develop a plan, they rarely follow it. (Johnson \& Reid, 2011). Students with ADHD will choose a strategy that requires the least amount of cognitive effort. They will require direct and explicit instruction in planning and using strategies (Johnson \& Reid, 2011, Daley \& Birchwood, 2009). Students with ADHD will also require practice and guidance until they master the particular skill or strategy. One cannot assume that students with ADHD will remember how to perform a task after receiving instruction on only one occasion. Repeated instruction and frequent check-ins are necessary. As students grow older, planning becomes more complicated and can happen over an extended time period (Guare, Dawson, \& Guare, 2013). Breaking down school projects and assignments into manageable parts will be critical for students with ADHD to successfully complete their assigned tasks.

\section{Goal Setting}

Students with ADHD have problems setting goals (Daley \& Birchwood, 2009). They are often unaware of the goal for a given academic task and/or have problems remembering what the goal was (Johnson \& Reid, 2011). In addition, students with ADHD will often focus on the wrong part of the task and this misplaced attention will inhibit their performance. Without goals, students with ADHD will have trouble putting their efforts and energy into being productive in their academic tasks. Goal setting needs to be "taught in the same manner as a strategy" (Johnson \& Reid, 2011, p. 64). During the goal setting process, teachers need to remember to keep goals specific (Johnson \& Reid, 2011) ensure that goals have a short time frame, and be somewhat challenging. By breaking down a larger goal into smaller, achievable parts, students will be successful and want to continue working toward their goal. Frequent check-ins and feedback will also encourage students to keep working on attaining their goal. 


\section{Persistence}

Students with ADHD have trouble self-regulating or showing persistence and is one of the last executive functioning skills to fully develop (Guare, Dawson, \& Guare, 2013; Johnson \& Reid, 2011). When students with ADHD encounter problems or roadblocks in their tasks, their first response is to quit the activity in which they are engaged. This result is often due to frustration and lack of progress monitoring of their activity. Johnson and Reid (2011) remind us that "students with ADHD are unaware of their progress on the task" (p. 65). Teachers can help students with ADHD build perseverance by ensuring that they have enough direction and time to practice the task successfully. Focusing on productivity, not accuracy, can improve the student's perseverance (Barkley, 2016). Teachers can also help students develop a positive "can-do" attitude. Furthermore, by teaching self-assessment and self-monitoring skills, teachers can show their students how much work they have accomplished. (Johnson \& Reid, 2011). In school, students with ADHD often do not see the point of activities and tasks that we ask them to do, and this affects their desire to continue with the task. Barkley (2013) and Guare, Dawson, \& Guare, (2013) suggest providing incentives to increase motivation and develop perseverance.

\section{Conclusion}

In taking all of these studies and resources together, we can conclude that, due to their inattention, students with ADHD typically have lower academic performance than do their neurotypical peers. The achievement gap between students with ADHD and their non-ADHD peers widen as students continue through the grades. The inattention aspect of ADHD impacts students' abilities to attend to direction, notice details in their tasks, complete their activities, and affect their organizational skills. While medications have been shown to help improve the learning behaviors of students, there has been little evidence towards impacting the academic performance and GPAs of students with ADHD. Students with ADHD show EF skill deficits, which also has shown effects on learning behaviors. By targeting increasing EF abilities of students with ADHD, there could be an influence on their learning behaviors, thus impacting student achievement. Bussing et al. (2012) remind us that "schools should develop early, ongoing, and systemic programming to deal with the needs of students with ADHD..." (p. 141). The impacts of on ADHD students' academic performance haves severe implications on the lives of these children. We owe it to these children not to let them fail. ADHD is a disorder that affects people for the entirety of their lives. By setting them up for success during their schooling, we can influence the lives of students with ADHD. 


\section{References}

American Psychiatric Association (2017, July). What is ADHD? https://www.psychiatry.org/patients-families/adhd/what-is-adhd

Barkley, R.A., (2013). Taking charge of ADHD: The complete, authoritative guide for parents ( $3^{r d} E d$.). New York: The Guilford Press:

Barkley, R.A., (2016). Managing ADHD in school: The best evidence-based methods for teachers. Eau Claire, WI.: PESI Publishing \& Media.

Bussing, R., Porter., P., Zima, B.T., Mason, D., Garvan, C. \& Reid, R. (2012). Academic outcome trajectories of students with ADHD: does exceptional education status matter? Journal of Emotional and Behavioral Disorders, 20(3), 131-143. Doi: 10.1177/1063426610388180

https://journals-sagepubcom.login.ezproxy.library.ualberta.ca/doi/pdf/10.1177/1063426610388180

Canadian ADHD Resource Alliance. (2019, November). Provincial and Federal Public Formulary Overview. CADDRA. https://www.caddra.ca/provincial-and-federal-public-formulary-overview/

Center for Disease Control and Prevention (2019, October). Data and Statistics about ADHD. https://www.cdc.gov/ncbddd/adhd/data.html

Colomer, C., Bergenguer, C., Rosello, B., Baixauli, I. \& Miranda, A. (2017). The impact of inattention, hyperactivity/impulsivity symptoms, and executive functions on learning behaviors of children with ADHD. Frontiers in Psychology, 8(540), 1-10. Doi:10.3389/fpsyg.2017.00540 https://www.frontiersin.org/articles/10.3389/fpsyg.2017.00540/full

Costa, D. D. S., Paula, J. J. D., Alvim-Soares Júnior, A. M., Diniz, B. S., Romano-Silva, M. A., Malloy-Diniz, L. F., \& Miranda, D. M. D. (2014). ADHD inattentive symptoms mediate the relationship between intelligence and academic performance in children aged 6-14. Brazilian Journal of Psychiatry, 36(4), 313-321.

Daly, D. \& Birchwood, J. (2009). ADHD and academic performance: Why does ADHD impact on academic performance and what can be done to support ADHD children in the classroom? Child: Care, Health and Development, 36(4), 455-464. Doi:10.111/j.1365-2214.2009.01046.x 
Dodson, W. (2019, June 19). How does ADHD medication work? Your first questions answered. ADDitude. https://www.additudemag.com/how-doesadhd-medication-work-common-treatment-qs/

Fan, X. (2001). Statistical significance and effect size in education research: Two sides of a coin. The Journal of Educational Research, 94(5), 275-282.

Fergusson D.M., Lynskey M.T. \& Horwood L.J. Attentional difficulties in middle childhood and psychosocial outcomes in young adulthood. (1997). The Journal of Child Psychology and Psychiatry. 38(6), 633-44. Doi: 10.1111/j.1469-7610.1997.tb01690.x. PMID: 9315973.

Grossberg, B. (2015). Focused: ADHD \& ADD parenting strategies for children with attention deficit disorder. Berkeley, CA.: Althea Press.

Guare, R., Dawson, P. \& Guare, C. (2013) Smart but scattered teens. New York: The Guildford Press.

Johnson. J., \& Reid, R. (2011). Overcoming executive function deficits with students with ADHD. Theory into Practice, 50, 61-67. Doi: 10.1080/00405841.2011.534942 https://eds.b.ebscohost.com/eds/pdfviewer/pdfviewer?vid=11\&sid=717fc3 4d-5fb9-4480-8a60-4e3d7bb08105\%40pdc-v-sessmgr02

Keilow, M., Holm, A. \& Fallesen, P. (2018). Medical treatment of attention deficit/hyperactivity disorder (ADHD) and children's academic performance. PLoS One, 13(11), 1-17. Doi: https://doi.org/10.1371/journal.pone.0207905

Klenberg, L., Hokkanen, L., Lahti-Nuuttila, P. \& Närhi, V. (2017) Teacher Ratings of Executive Function Difficulties in Finnish Children with Combined and Predominantly Inattentive Symptoms of ADHD. Applied Neuropsychology: Child, 6(4), 305-314. Doi: 10.1080/21622965.2016.1177531

Lundervold, A. J., Meza, J. I., Hysing, M. \& Hinshaw, S.P. (2017). Parent rated symptoms of inattention in childhood predict high school academic achievement across two culturally and diagnostically diverse samples. Frontiers in Psychology, 8, 1-9. Doi: 
https://doi.org/10.3389/fpsyg.2017.01436

https://www.frontiersin.org/articles/10.3389/fpsyg.2017.01436/full

McCormick, L.H. (2003). ADHD treatment and academic performance: A case study. The Journal of Family Practice, 52(8), 620-626. https://mdedgefiles-live.s3.us-east-2.amazonaws.com/files/s3fspublic/Document/September-2017/5208JFP_BriefReport1.pdf

Miklos, M., Futo, J., Komaromy, D. \& Balazs, J. (2019). Executive function and attention performance in children with ADHD: Effects of medication and comparison with typically developing children. International Journal of Environmental Research and Public Health, 16(20), 3822. Doi: 10.3390/ijerph16203822 https://www.mdpi.com/1660-4601/16/20/3822

Perrin, H.T., Heller, N.A. \& Loe, I.M. (2019). School readiness in preschoolers with symptoms of attention-deficit/hyperactivity disorder. Pediatrics, 144(2), 1-9. Doi: 10.1542/peds.2019-0038: https://pediatricsaappublicationsorg.login.ezproxy.library.ualberta.ca/content/144/2/e20190038

Prasad, V., Brogan, E., Mulvaney, C., Grainge, M., Stanton, W. \& Sayal, K. (2013). How effective are drug treatments for children with ADHD at improving on-task behavior and academic achievement in the school classroom? A systematic review and meta-analysis. European Child \& Adolescent Psychiatry, 22, 203-216. Doi: 10.1007/s00787-012-0346-x

Santosh, B.R. \& Rachana, N. (2019). Impact of attention deficit disorder on academic performance of children. Indian Journal of Public Health Research \& Development, 10(4), 179-184. Doi: 10.5958/09765506.2019.00686.7

Schmiedeler, S. \& Schneider, W. (2014). Attention-deficit hyperactivity disorder (ADHD) in the early years: Diagnostic issues and educational relevance. Clinical Child Psychology, 19(3), 460-475. Doi: $10.1177 / 1359104513480079$

Takri, B.B. \& Jaiswal, J. (2019). Academic performance of students with attention deficit hyperactivity disorder (ADHD) and students without ADHD. International Journal of Engineering Development and Research, 7(2), 87-90. https://www.ijedr.org/papers/IJEDR1902019.pdf 
van der Donk, M.L.A., Hiemstra-Beernink, A.C., Tjeenk-Kalff, A.C., van der Leij, A.V. \& Lindauer, R.JL. (2013). Interventions to improve executive functioning and working memory in school-aged children with $\mathrm{AD}(\mathrm{H}) \mathrm{D}$ : a randomized control trial and stepped-care approach. BMC Psychiatry, 13(23), 1-7. 